\title{
Landsat satellite derived environmental metric for mapping mosquitoes breeding habitats in the Nkomazi municipality, Mpumalanga Province, South Africa
}

\author{
A.M. Adeola ${ }^{\star}{ }^{*}$, J.M. Olwoch ${ }^{b}$, J.O. Botai ${ }^{a}$, C.J. deW Rautenbach ${ }^{a}$, A.M. Kalumba ${ }^{\text {, P.L. }}$ \\ Tselaa, O.M. Adisa ${ }^{a}$ and F.W.N. Nsubuga ${ }^{a}$
}

aDepartment of Geography, Geoinformatics and Meteorology, University of Pretoria, Hatfield, South Africa; bEarth Observation Directorate, South African Space Agency (SANSA), Silverton, South Africa

Correspondence to: A.M. Adeola email: Adeola.Abiodun@tuks.co.za

\begin{abstract}
The advancement, availability and high level of accuracy of satellite data provide a unique opportunity to conduct environmental and epidemiological studies using remotely sensed measurements. In this study, information derived from remote sensing data is used to determine breeding habitats for Anopheles arabiensis which is the prevalent mosquito species over Nkomazi municipality. In particular, we have utilized the normalized difference vegetation index (NDVI) and normalized difference water index (NDWI) coupled with land surface temperature (LST) derived from Landsat 5 TM satellite data. NDVI, NDWI and LST are considered as key environmental factors that influence the mosquito habitation. The breeding habitat was derived using multi-criteria evaluation (MCE) within ArcGIS using the derived environmental metric with appropriate weight assigned to them. Additionally, notified malaria cases were analysed and spatial data layers of water bodies, including rivers and dams, were buffered to further illustrate areas at risk of malaria. The output map from the MCE was then classified into three classes which are low, medium and high areas. The resulting malaria risk map depicts that areas of Komatieport, Malelane, Madadeni and Tonga of the district are subjected to high malaria incidence. The time series analysis of environmental metrics and malaria cases can help to provide an adequate mechanism for monitoring, control and early warning for malaria incidence.
\end{abstract}

Keywords: Remote sensing; geographic information system; multi-criteria evaluation; environmental; NDVI; NDWl; LST; malaria

\section{Introduction}

Malaria is classified as one of the major health problems globally; it is estimated that there are about 300-500 million cases and about one million deaths associated to malaria annually, with a larger percentage of malaria cases and deaths occurring in sub-Saharan Africa (WHO, 2013a). However, there is a significant reduction in malaria cases and its associated death as a result of the use of Insecticide-treated mosquito nets (ITNs) and Indoor residual 
spraying (IRS) (WHO, 2013a; WHO, 2013b). According to STATS SA, (2009) about 4.9 million of the population representing $10 \%$ of the total population live in malariaendemic area in South Africa. Malaria is majorly endemic in three provinces: Limpopo, Mpumalanga and KwaZulu-Natal. But, occasionally few major occurrences are sighted in northern Cape and north-west provinces along Orange and Molopo rivers as a result of the provision of suitable breeding habitats for mosquitoes to survive (Department of Health, South Africa, 2007). Plasmodium falciparum accounts for about $95 \%$ of the total malaria infections in South Africa through Anopheles arabiensis as the major local vector.

Studies have shown that there is a direct link between environmental and climatic param-eters and malaria incidences (Ceccato, Connor, Jeanne, \& Thomson, 2005; Machault et al., 2011). This implies that the spatial and temporal distribution as well as the abundance of mosquitoes can be substantively determined by considering environmental parameters (e.g. vegetation, elevation and water body type) and climatic parameters (e.g. temperature, rainfall and humidity) which could, in addition to terrestrial measurements, be derived from satellite data (Hay et al., 1998).

The use of remotely sensed data to investigate, describe and predict the spatial and temporal patterns of the transmission and prevalence of vector-borne diseases has been widely studied in the past years (Beck et al., 2000; Machault et al., 2011; Rogers, Randolph, Snow, $\&$ Hay, 2002). The goal of using such data could be to map vector densities or to detect breeding habitats of organisms responsible for vector-borne diseases, for example, to define and identify environmental parameters that are associated with mosquito distribution and malaria occurrences (see e.g. Zou, Miller, \& Schmidtmann, 2006). Satellite derived land surface temperature (LST) and indices like normalized difference vegetation index (NDVI) and normalized difference water index (NDWI) can be used as surrogate data for malaria studies (Hopp \& Foley, 2001). Such studies provide continuous data and offer the possibility of identifying mosquitoes' breeding habitats over large areas in contrast to conventional ground surveys (Bogh et al., 2007; Hay, Snow, \& Rogers, 1998). The mapping of the spatiotemporal distribution of mosquito breeding habitats is regarded as crucial for reducing incidences of malaria ( $\mathrm{Gu} \&$ Novak, 2005).

Eisele et al. (2003) demonstrated that NDVI values derived from multispectral thermal imagery overlaid on georeferenced entomological and human ecological data can be used to determine malaria prevalence in an urban area. Gaudart et al. (2009) used 15-day composite NDVI coupled with a field study to derive a malaria transmission model. They found that the seasonal pattern of $P$. falciparum incidence was significantly explained by NDVI. Similar studies have also been conducted in South and Central America (Britch et al., 2008) and Asia (Adimi, Soebiyanto, Safi, \& Kiang, 2010; Charoenpanyanet \& Chen, 2008; Masuoka, Claborn, Andre, \& Nigro, 2003).

Malaria study in South Africa has witnessed great input from researchers like (Booman et al., 2000, 2003; Coleman et al., 2008; Kleinschmidt, Sharp, Clarke, Curtis, \& Fraser, 2001; Le Sueur et al., 1994, 1997; Martin, Curtis, Fraser, \& Sharp, 2002; Sharp, Fraser, \& Naidoo, 1999, 2000) to mention but a few. However, the majority of these studies are based on statistical analysis and the use of Geographic Information System (GIS). For instance, (Kleinschmidt et al., 2001) use generalized linear mixed models to spatially analyse malaria incidence rate in KwaZulu-Natal. Sharp et al. (1999) developed a computer-assisted health information system for malaria control. Also, Martin et al. (2002), developed a GIS-based malaria information system. However, the advantages offered by the use of remote sensing has not been utiozed in any of these studies. In 
addition, the majority of the works have been focused on KwaZulu-Natal Province which is one of the three malaria-endemic prov-inces. The aim of this study is to identify the potentially favourable breeding habitats of the mosquito using environmental metric parameters derived from Landsat satellite imagery over the Nkomazi municipality in the Mpumalanga Province of South Africa. The envi-ronmental parameters have applications in the development of a malaria risk prediction model for the region.

\section{Study area}

The Nkomazi municipality is situated in the eastern part of the Mpumalanga Province of South Africa and occupies an area of approximately $3254 \mathrm{~km}^{2}$ (Figure 1). The Mpumalanga Province is one of the malaria-endemic provinces in South Africa (National Department of Health, 2007). The Province covers a surface area of $77918.298 \mathrm{~km}^{2}$ which constitutes about $6.5 \%$ of the country's land area. According to the mid-year population estimates for 2013, the province had 4,128,000 which constitutes $7.8 \%$ of South Africa's total population (Statistics South Africa, 2013). The climatology of the Mpumalanga Province consists of a relatively cool western half, which is often associated to its higher elevation of 1700-2300 m above mean sea level. The eastern half is situated in subtropical low-altitude topography, known as the Lowveld/Bushveld. This area is dominated by Savannah habitats as a result of its closeness to the warm Indian Ocean. The Kruger National Park is located in the Lowveld/Bushveld.

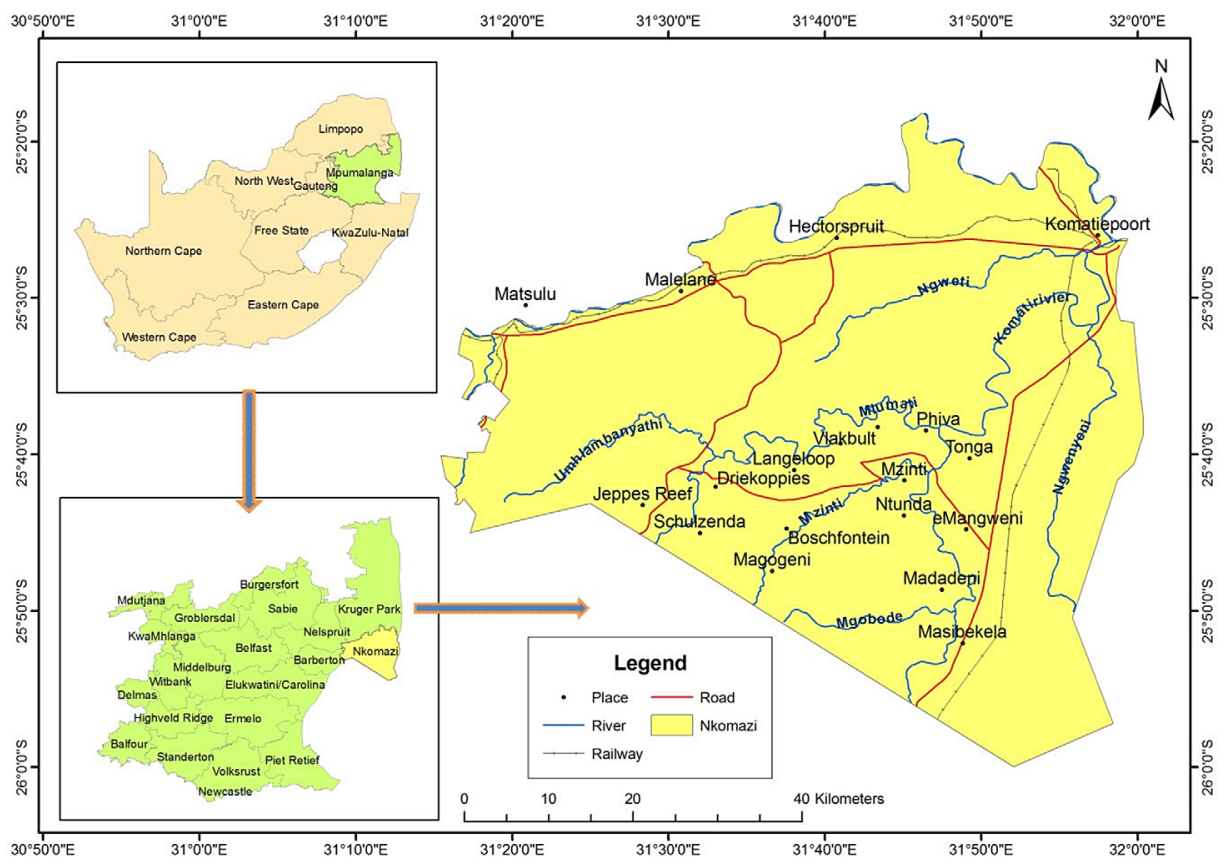

Figure 1. Maps of the study area depicting the Nkomazi municipality (right) located in the eastern parts of the Mpumalanga Province (left bottom) of South Africa (left top). (source: Author) 


\section{Material and methods}

\section{Data}

\section{Landsat data}

A summer cloud-free Landsat Thematic Mapper (TM) image of 1998/02/07 of path/row 168/078 was downloaded from the archive of Global Land Cover Facility hosted by the University of Maryland. Only the TM Spectral Band $2(0.52-0.60 \mu \mathrm{m})$, Spectral Band 3 $(0.63-0.69 \mu \mathrm{m})$, Spectral Band $4(0.76-0.90 \mu \mathrm{m})$, Spectral Band $5(1.55-1.75 \mu \mathrm{m})$ and Spectral Band $6(10.4-12.5 \mu \mathrm{m})$ of the image were considered in this study. All these have a spatial resolution of $30 \times 30 \mathrm{~m}$, except for the thermal Spectral Band 6, which has a resolution of $60 \times 60 \mathrm{~m}$.

\section{Malaria data}

Malaria data from September 1997 to August 1998 was used. The data was obtained from the provincial integrated malaria information system (IMIS) of malaria control programme in the Mpumalanga provincial department of health. These data mainly consist of locally recorded incidences with minimal imported cases that were extracted from IMIS at clinics and hospitals at the district level. The health facilities as shown in Figure 6 are approximately $10 \mathrm{~km}$ apart.

\section{Ancillary spatial data}

Spatial data of various sources of water which included streams, rivers and dams (wetlands) were acquired for the study area.

\section{Methods}

\section{Pre-processing}

All the selected Landsat TM satellite image bands were defined in Universal Transverse Mercator (UTM Zone 36S) projections. Erdas Imagine 9.1 raster-based software was used for image processing and analyses (Qinqin, Jianjun, \& Yonghang, 2010). The images were received at level $1 \mathrm{~T}$, so were already geo-rectified. Bands 6 , the thermal band was resampled to pixel size of 30 by $30 \mathrm{~m}$ using the nearest neighbour algorithm with root mean square error (RMSE) of less than 0.5 pixels. An area of interest of $3254.041 \mathrm{~km}^{2}$ representing the total area of Nkomazi municipality was extracted for each required spectral band of the image (Figure 1). The Spatial Modeler of Erdas Imagine 9.1 was used to convert the digital numbers (DNs) of the selected spectral bands (2, 3, 4 and 5) to radiance using Equation (1) (Landsat Project Science Office, 2002). Subsequently, the exoatmospheric reflectance values were derived using Equation (2) (Gyanesh, Brian, \& Dennis, 2009). The DN of thermal spectral Band 6 was also converted to radiance using Equation (1). Equation (3) was used to derive the at-sensor brightness temperature (BT) and Equation (6) was used to derive the emissivity-corrected LST with a unity value of 0.95 for spectral emissivity.

In other to achieve a physically meaningful radiometric scale, the image data of all the selected bands were converted to at-sensor spectral radiance (Gyanesh et al., 2009). Equation (1) was used to radiometrically calibrate the TM image.

$$
L_{\lambda}=\left(\frac{\operatorname{LMAX}_{\lambda}-\mathrm{LMIN}_{\lambda}}{Q_{\text {calmax }}-Q_{\text {calmin }}}\right)\left(Q^{\mathrm{cal}}-Q_{\text {calmin }}\right)+\operatorname{LMIN}_{\lambda}
$$


Table 1. $\operatorname{LMAX}_{\lambda}, \operatorname{LMIN}_{\lambda}$ and ESUN values of Landsat TM satellite data.

\begin{tabular}{lccc}
\hline Band no & $\operatorname{LMAX}_{\lambda}$ & $\operatorname{LMIN}_{\lambda}$ & $\operatorname{ESUN}_{\lambda}$ \\
\hline 2 & 365 & -2.84 & 1796 \\
3 & 264 & -1.17 & 1536 \\
4 & 221 & -1.51 & 1031 \\
5 & 30.2 & -0.37 & 220 \\
6 & 15.3032 & 1.2378 & - \\
7 & & & 83.44 \\
\hline
\end{tabular}

Source: Metadata file of the image and Gyanesh et al., (2009).

where $L_{\lambda}=$ spectral radiance at the sensor's aperture $\left[\mathrm{W} /\left(\mathrm{m}^{2} \mathrm{sr} \mu \mathrm{m}\right)\right], Q_{\text {cal }}=$ quantized calibrated pixel value $(\mathrm{DN}), Q_{\text {calmin }}=$ minimum quantized calibrated pixel value corresponding to $\operatorname{LMIN}_{\lambda}(\mathrm{DN}), Q_{\text {calmax }}=$ maximum quantized calibrated pixel value corresponding to $\operatorname{LMAX}_{\lambda}(\mathrm{DN}), \operatorname{LMIN}_{\lambda}=$ spectral at-sensor radiance that is scaled to $Q_{\text {calmin }}\left[\mathrm{W} /\left(\mathrm{m}^{2} \mathrm{sr} \mu \mathrm{m}\right)\right]$, $\operatorname{LMAX}_{\lambda}=$ spectral at-sensor radiance that is scaled to $Q_{\text {calmax }}\left[\mathrm{W} /\left(\mathrm{m}^{2} \mathrm{sr} \mu \mathrm{m}\right)\right] . \mathrm{LMAX}_{\lambda}$ and LMIN $_{\lambda}$ are obtained from the Metadata file available with the image, which are given in Table 1.

Equation (2) was used to convert the spectral radiances of the selected bands (2, 3, 4 and $5)$ to planetary reflectance or albedo which is a physical measurement to achieve a reduction in between-scene variability (Gyanesh et al., 2009). The mean solar exoatmospheric irradi-ances (ESUN) measured in $\left[\mathrm{W} /\left(\mathrm{m}^{2} \mu \mathrm{m}\right)\right]$ are shown in table 1 given in Gyanesh et al., (2009).

$$
\rho=\frac{\pi \times L_{\lambda} \times d^{2}}{\operatorname{ESUN}_{\lambda} \times \cos \theta_{s}}
$$

where $\rho=$ planetary TOA reflectance (unitless), $\pi=$ mathematical constant equal to 3.14159 (unitless), $L_{\lambda}=$ spectral radiance at the sensor's aperture $\left[\mathrm{W} /\left(\mathrm{m}^{2} \mathrm{sr} \mu \mathrm{m}\right)\right], d=$ earth-sun distance (astronomical units), $\mathrm{ESUN}_{\lambda}=$ mean exoatmospheric solar irradiance $\left[\mathrm{W} /\left(\mathrm{m}^{2} \mu \mathrm{m}\right)\right]$, $\theta_{s}=$ solar zenith angle $\left(^{\circ}\right)$.

Note: The cosine of the solar zenith angle is equal to the sine of the solar elevation angle.

\section{Deriving NDVI, NDWI and LST from the Landsat TM satellite}

After the radiometric calibration of the image data, the NDVI, NDWI and LST were derived from the image. These methods are defined using Equations (3), (4) and (5), respectively. The NDVI calculation is given in Equation (3) where $\rho$ RED and $\rho$ NIR correspond to the reflectance measured in band $3(0.63-0.69 \mu \mathrm{m})$ and band $4(0.77-0.90 \mu \mathrm{m})$, respectively (Rouse, Haas, Schell, \& Deering, 1973). Generally NDVI ranges from -1 to +1 , where water typically has an NDVI less than 0 , bare soil between 0 and 0.1 and vegetation greater than 0.1 .

$$
\mathrm{NDVI}=\frac{\rho \mathrm{NIR}-\rho \mathrm{RED}}{\rho \mathrm{NIR}+\rho \mathrm{RED}}
$$

The NDWI calculation is given in Equation (4) where $\rho$ Green and $\rho$ SWIR correspond to the reflectance measured in band $2(0.52-0.60 \mu \mathrm{m})$ and band $5(1.55-1.75 \mu \mathrm{m})$, respectively $(\mathrm{Xu}, 2006)$. In summary, NDWI is positive for all water features and negative for all other land features.

$$
\mathrm{NDWI}=\frac{\rho \text { Green }-\rho \mathrm{SWIR}}{\rho \text { Green }+\rho \mathrm{SWIR}}
$$




\section{Land surface temperature}

The LST was derived from the thermal infrared (IR) band of the Landsat image (Colombi, De Michele, Pepe, Rampini, \& Rossi, 2007; Vancutsem, Ceccato, Dinku, \& Connor, 2010). Equation (5) was used to convert the spectral radiance to at-satellite brightness temperature $\left(T_{B}\right)$ under the assumption of uniform emissivity (Landsat Project Science Office, 2002). Equation (6) was used to derive the emissivity-corrected LST using a unity value of 0.95 as the spectral emissivity (Artis \& Carnahan, 1982).

$$
T_{B}=\frac{K_{2}}{\ln \left(\frac{K_{1}}{L_{\lambda}}+1\right)}
$$

where $T_{B}$ is the effective at-sensor brightness temperature in Kelvin, $L_{\lambda}$ is the spectral radiance in $\mathrm{W} /\left(\mathrm{m}^{2}\right.$ ster $\left.\mu \mathrm{m}\right)$; and $K_{1}$ and $K_{2}$ are pre-launch calibration constants given as $K_{1}=607.76\left(\mathrm{~W} /\left(\mathrm{m}^{2}\right.\right.$ ster $\left.\mu \mathrm{m}\right)$ and $K_{2}=1260.56$ (Kelvin), ln = natural logarithm.

$$
\mathrm{LST}=\frac{T_{B}}{1+\left(\lambda \times T_{B} / \rho\right) \ln \varepsilon}
$$

where $\lambda$ is the wavelength of the emitted radiance $(11.5 \mu \mathrm{m}) . \rho=$ h.c $/ \sigma, \sigma=$ Stefan Boltzmann's constant $\left(5.67 \times 10^{-8} \mathrm{Wm}^{-2} \mathrm{~K}^{-4}\right), h=$ Plank's constant $\left(6.626 \times 10^{-34} \mathrm{JS}\right), c=$ velocity of light $\left(2.998 \times 10^{8} \mathrm{~m} / \mathrm{s}\right)$ and $\varepsilon$ is the spectral emissivity.

\section{Proximity analysis}

Rivers and dams were buffered in ranges of 2.4 and $3.2 \mathrm{~km}$ to define areas of high and low risk, respectively, based on the determined flight range of the Anopheles mosquitoes. The flight direction, speed and consequently the range of individual mosquitoes is influenced by the wind (Cummins, Cortez, Foppa, Walbeck, \& Hyman, 2012) and other anthropological factors like topography (Stephen, 2006). Habitually, adult Anopheles mosquitoes do not fly beyond $2.4 \mathrm{~km}$ from their larval habitat with only a small proportion flying farther than $3.2 \mathrm{~km}$. The population within $2.4 \mathrm{~km}$ radius of the rivers and dams are termed to be more susceptible to be bitten by mosquitos.

\section{Clinical data analysis}

The malaria data from September 1997 to August 1998 which tallies with the year of the image used for this paper was statistically analysed. Descriptive analysis showing the temporal variation of malaria cases across the health facility centres were cases were reported was performed. Figure 7 illustrates the temporal and spatial variation of malaria cases across the study area.

\section{Multi-criteria evaluation (MCE)}

MCE analysis was performed in order to create a spatial distribution of mosquito breeding habitats and risk map. MCE is a procedure that requires the combination of several criteria to be weighed to meet a particular objective. In order to determine the weight to be assigned to the derived environmental metric (NDVI, NDWI and LST), eigenvector was used. This is done to determine the importance of each metric compared to each other in the contribution of generating a malaria risk map. Hence, the eigenvector of the weight of 
Table 2. Classification of remotely sensed derived environmental metric for input to create malaria risk map.

\begin{tabular}{lccc}
\hline & Risk score & Risk level & Source \\
\hline LST $\left({ }^{\circ} \mathrm{C}\right)$ & & Very low & Bi et al. (2003) \\
$<16.0$ & 1 & Low & \\
$16.1-20.0$ & 2 & Moderate & \\
$20.1-25.0$ & 3 & High & \\
$25.1-30.0$ & 4 & & \\
$>30.1$ & 2 & Very low & Nihei, Hashida, Kobayashi, and Ishii (2002) \\
NDVI (Unitless) & & Hay et al. (1998) \\
$<0.2$ & 1 & Loderate & \\
$0.21-0.30$ & 2 & High & \\
$0.31-0.40$ & 3 & Low & \\
$0.41-0.50$ & 4 & & \\
$>0.51$ & 2 & Very Low & \\
$N D W I$ (Unitless) & & Low & \\
$<=0.00$ & 1 & Moderate & High \\
$0.01-0.20$ & 2 & 3 & \\
$0.21-0.30$ & 4 & & \\
$0.31-0.80$ & & & \\
\hline
\end{tabular}

the metric was calculated in ArcGIS. The result of the eigenvector gives a pair-wise comparison matrix of NDVI 0.1520, NDWI 0.3436 and LST 0.1317 as a best fit set of weights. The environmental metric was reclassified using a threshold as derived from the analysis and supported by previous findings. Table 2 gives a summary of the various thresholds and classes that was combined to develop the risk map. The standardized metric was then combined by means of weighted linear combination (Eastman et al., 1995). The resulting map (breeding habitat) was then reclassified into three classes: (1) high, (2) medium and (3) low areas, to produce the risk map.

\section{Results and discussion}

Generally, water typically has an NDVI of less than 0 , bare soil between 0 and 0.1 and vegetation $>0.1$ (Rouse et al., 1973). As shown in Figure 2(A), the NDVI has a minimum value of -0.61 , a maximum value of 0.81 , mean value of 0.49 and standard deviation of 0.13 . The 0.81 value depicts healthy or dense vegetation. The densely vegetated areas are seen in Tonga, Komartiepoort and Masibekela of the study area. A threshold of NDVI 0.35 was set to distinguish vegetation from other features (Hay et al., 1998). Hence, NDVI $<0.5$ but $\geq 0.31$ implies area that could be mosquito's potential breeding habitat. Similarly, NDWI has positive value for water features and zero or negative value for other land features. It has a minimum value of -0.72 and a maximum value of 0.84 ; see Figure $2(\mathrm{~B})$. The study area is majorly drained by river Komati and in order to accommodate other water features like wetland and ponds a threshold of 0.3 was used. Therefore, NDWI $\geq 0.3$ equals water sources, which could be potential breeding habitat for mosquito (McFeeters, 2013).

The LST distribution over the study area is shown in Figure 3. Temperature has been proven to be one of the major indicators for the development and survival of Plasmodium parasite as well as developmental cycle and the survival of malaria-carrying mosquito (Bi, Tong, Donald, Parton, \& Ni, 2003; Machault et al., 2011). For Anopheles mosquito species, at $25^{\circ} \mathrm{C}$; the $P$. vivax, has a survival duration of about 10 days. The 

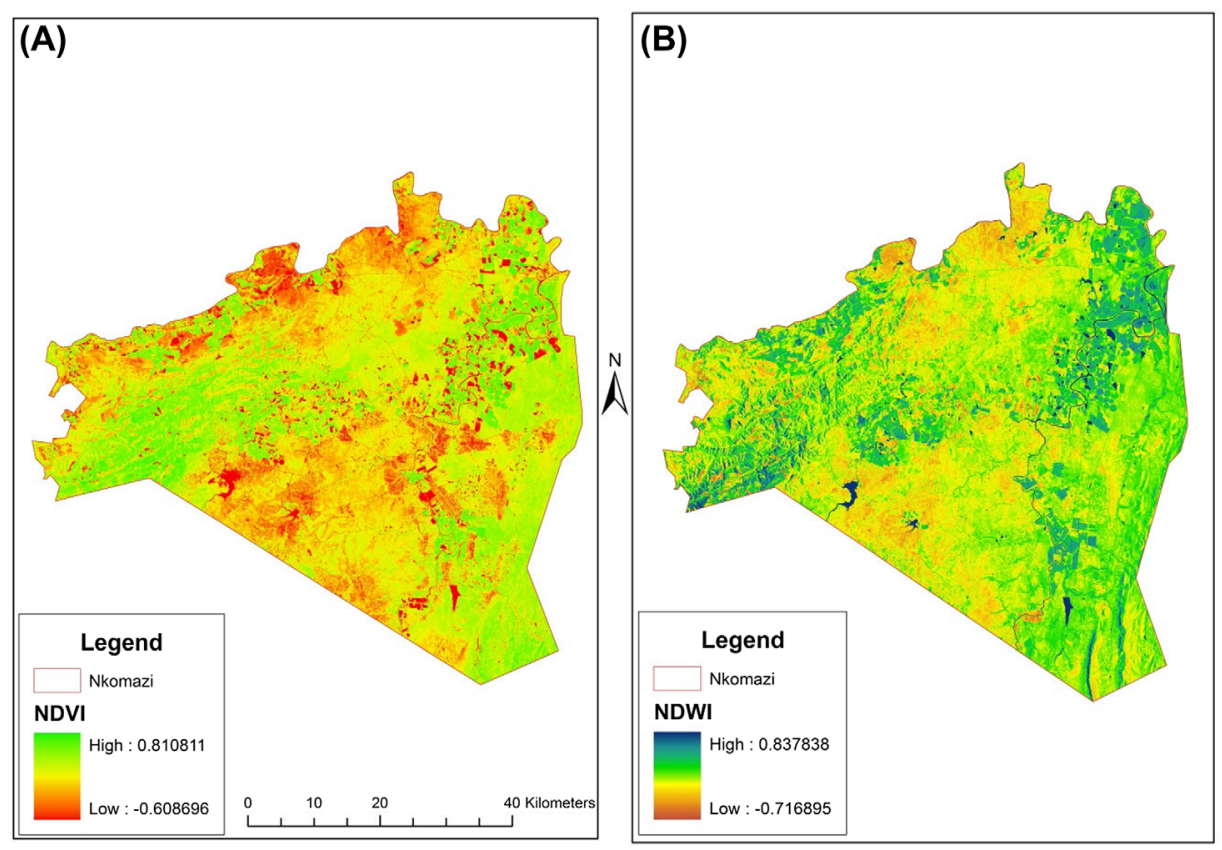

Figure 2. Two output maps from Landsat TM satellite data in the Nkomazi municipality area, (A) the NDVI and (B) MNDWI. (source: Author)
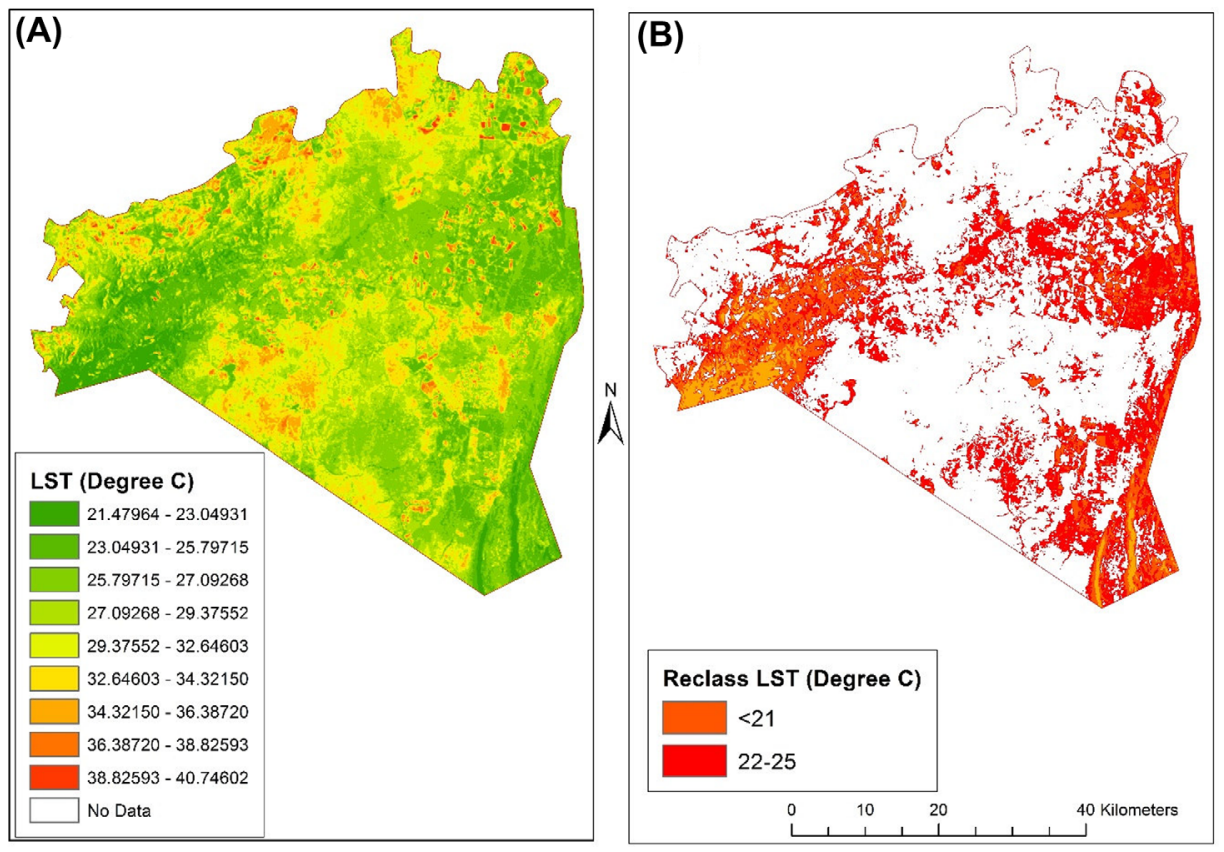

Figure 3. Two output maps from Landsat TM satellite data in the Nkomazi municipality area showing, (A) LST in degree Celsius and (B) reclassified LST based suitability map. (source: Author) 
Table 3. Temperature ranges that determine the survival of mosquito, (Bi et al. 2003).

\begin{tabular}{ll}
\hline Temperature range $\left(C^{\circ}\right)$ & Description \\
\hline$>25$ & Needed to complete the mosquito lifecycle and must be maintained for at least nine days \\
$20-30$ & Optimal temperature range to acquire and transmit the parasite \\
$20-27$ & $\begin{array}{l}\text { The extrinsic incubation period of the parasite shortens dramatically } \\
\leq 16 \text { or } \geq 30\end{array}$ \\
& $\begin{array}{l}\text { Negative impact on the growth rate of the mosquito and the propagation rate of the } \\
\text { parasite is reduced }\end{array}$ \\
\hline
\end{tabular}
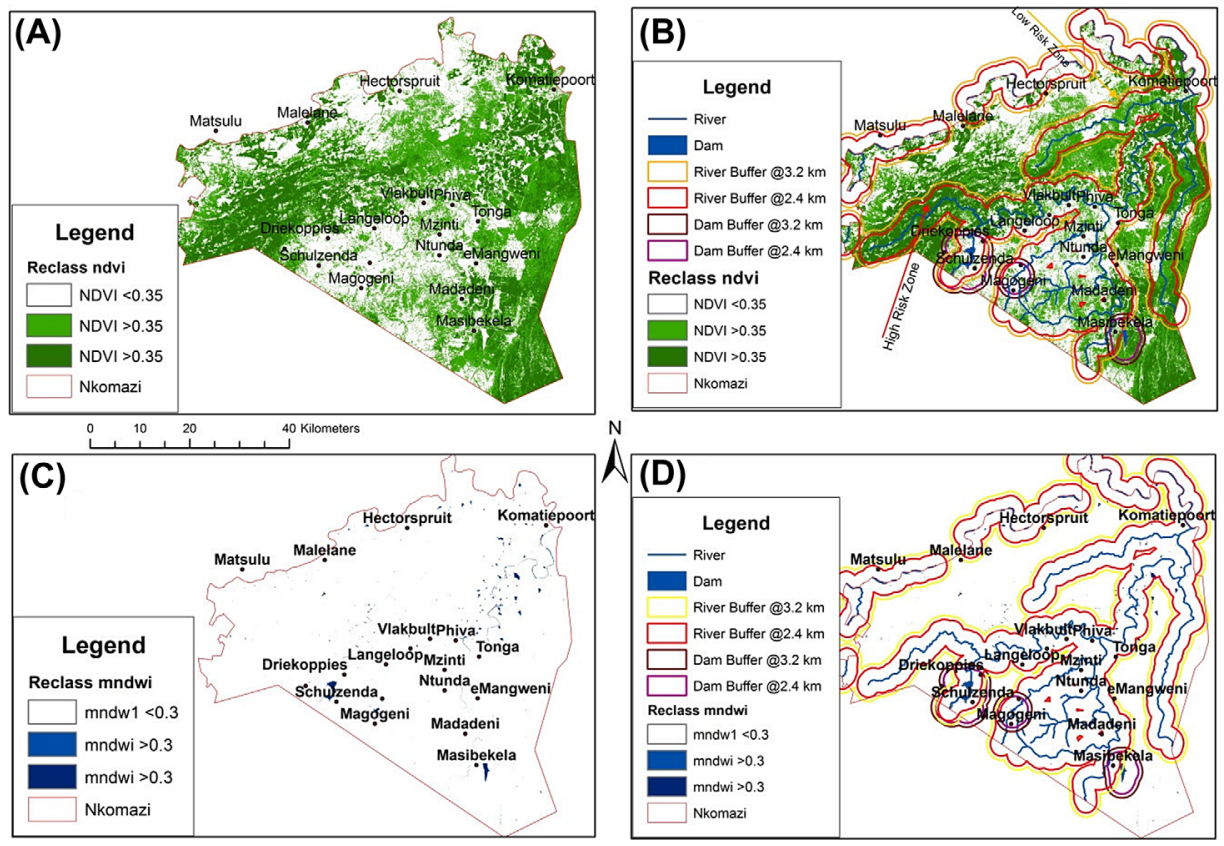

Figure 4. Four output maps from Landsat TM satellite data in the Nkomazi municipality area showing, (A) reclassified NDVI, (B) malaria risk map in relation to NDVI and proximity to natural water sources, (C) reclassified MNDWI and (D) malaria risk map in relation to MNDWI and proximity to natural water sources. (source: Author)

associated survival duration is 8-14 days for P. falciparum and 18-20 days for P. ovale and P. Malariae (Mouchet et al., 2004). In P. falciparum, the larvae can withstand even low temperatures, but do not com-plete their development at temperatures below 10$13^{\circ} \mathrm{C}$ and no appreciable development takes place until the temperature reaches $18-23^{\circ}$ C. Therefore, slight increases or decreases in temperature (from a benchmark of $16^{\circ} \mathrm{C}$ ) negatively impact the development of the parasite (Sutherst 2004). The LST indicates a minimum value of $21.48^{\circ} \mathrm{C}$, a maximum value of $40.75^{\circ} \mathrm{C}$, a mean value of $27.95^{\circ} \mathrm{C}$, and $2.40^{\circ} \mathrm{C}$ as the standard deviation. Table 3 gives the summary of temperature ranges that determine the life cycle and transmission of malaria-carrying mosquitoes. These temperature ranges are integrated as class break values for the LST variable that govern the MCE analysis to use to derive the risk map in ArcGIS. From the image, the densely vegetated areas have the lowest average temperature value of $22.3^{\circ} \mathrm{C}$, while water surface has an average of $22.6^{\circ} \mathrm{C}$, the built-up areas have an average of $29^{\circ} \mathrm{C}$ and bare land with the highest LST. In consideration of the maximum and minimum temperature needed for 


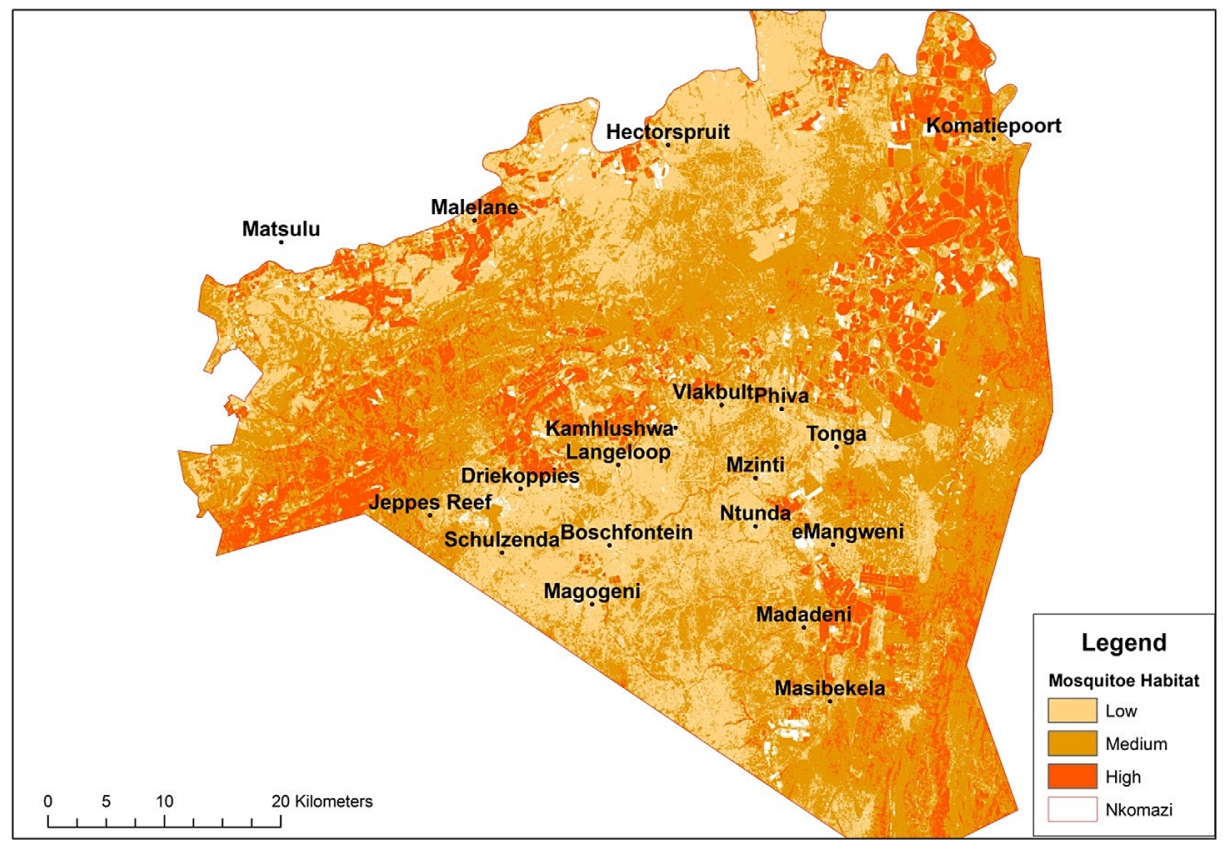

Figure 5. Malaria risk map as derived from environmental metric using Landsat satellite in the Nkomazi municipality. (source: Author)

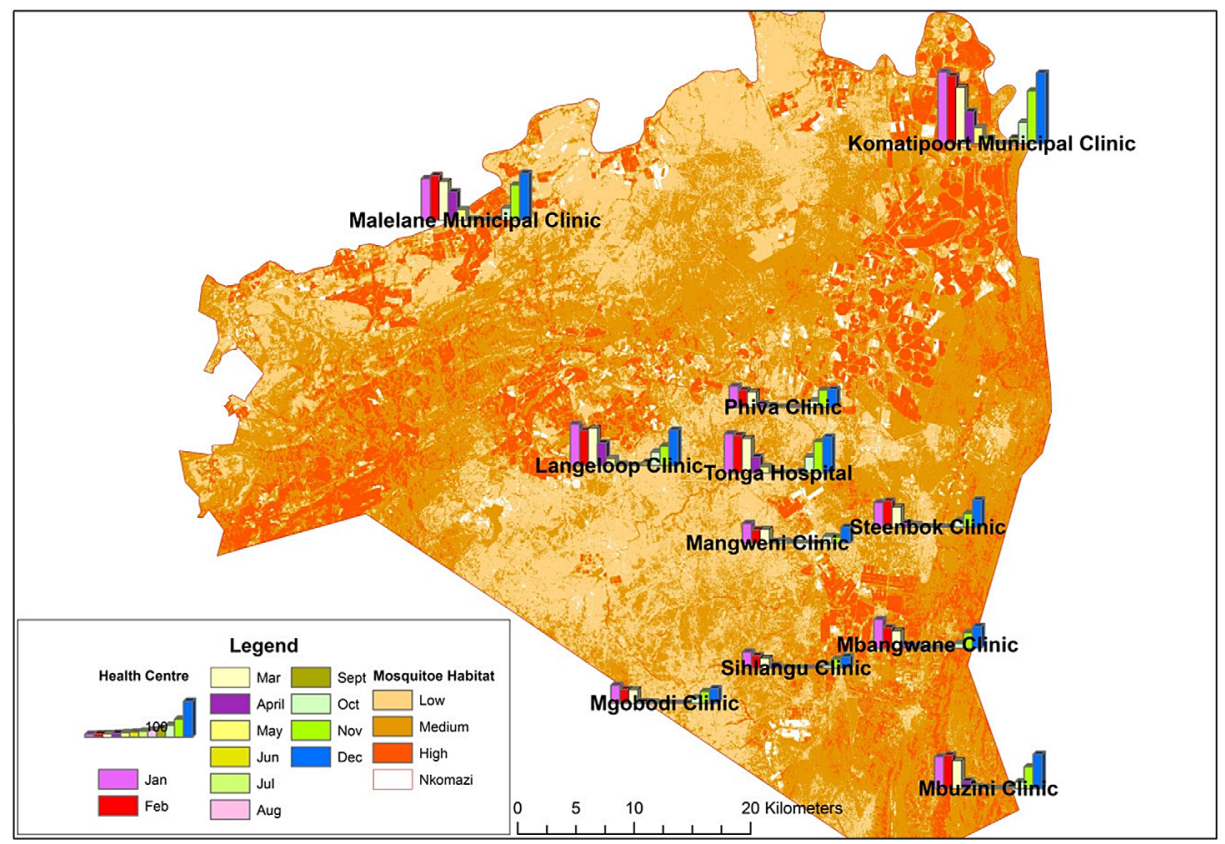

Figure 6. Malaria risk map in relation to malaria cases from September 1997 to August 1998 in the Nkomazi municipality. (source: Author) 


\section{Variation of malaria cases across the recording health facilitiy} centres

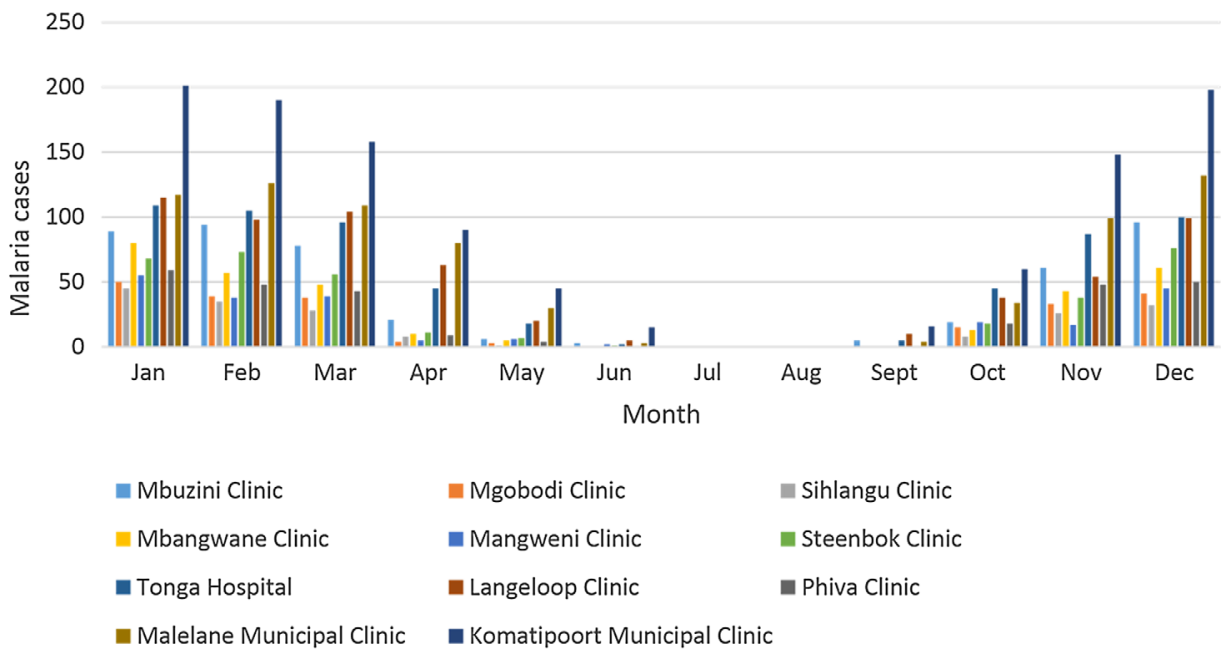

Figure 7. Variation of malaria cases across the recording health facility centres in the study area.

the breeding and survival of the vector, a threshold of $22-25^{\circ} \mathrm{C}$ was set for the LST Mouchet et al. (2004) and Sutherst (2004). In addition, the buffering analysis as shown in Figure 4(B) and (D), indicate that human population within $2.4-\mathrm{km}$ buffer zone where NDVI $\geq 0.35$ with the presence of water body are more susceptible to be bitten by the infected vector and, therefore, become infected. On the other hand, human population farther away from the suitable breeding sites are at lesser risk to a mosquito bite and less prone to malaria except when there is migration factor by the human population.

From the MCE, suitable breeding habitats were derived and reclassified into three classes shown in Figures 5 and 6, respectively. The high areas include Komatiepoort, Malelane, Madadeni and Tonga; medium include, Jeppes Reef, Masibekela and the Low areas include Langeloop, Ntunda and Driekoppies.

In addition, the output (the risk map) shows an association with malaria cases recorded in health centres within Nkomazi municipality; from September 1997 to August 1998, which corresponds to the year of Landsat 5 TM image used for this study. Within the malaria season, September-May (Department of Health, report 2007), a total of 5119 cases and 28 deaths were recorded. The month of January has the highest number of malaria cases while March has the highest number of deaths. Komatipoort clinic followed by Malelane clinic recorded the highest cases of malaria. From the record and as shown in Figure 7, there was a sudden rise in malaria cases between November and March which correspond with months when thresholds for mosquito's breeding are met (see Table 2).

\section{Conclusions}

Remotely sensed data can serve as a surrogate data when physically measured climatic data are not easily available (Ceccato et al., 2005). Mosquito breeding habitat (hence a risk map) is mapped by depending on some of the environmental factors which contribute to the development and survival of Anopheles mosquitoes. For the purpose of 
identifying areas of malaria risk, this study overlays remotely sensed environmental variables in appropri-ate weight and determines the spatial distance to conducive temperature area, distance to the potential vegetated area and wet area as the factors of malaria incidence in the study area. The malaria incidence and transmission requires the environment with moderate temperature, moderate-to-high vegetation cover, availability of wetlands, availability of still waters and areas of lower drainage density. The overlay analysis was done after each environmental metric was given appropriate weight in relation to the degree of significance that they have for the incidence of malaria in this research. Therefore, this study has demon-strated the identification of potential breeding habitats of mosquitoes within the Nkomazi municipality using Landsat-derived NDVI, NDWI and LST images as key environmental indicators during the summer season of 1998. From the analysis, the study area is largely within a permissible threshold of environmental metric favourable for the breeding of mosquito. The result of the eigenvector indicates that LST is the most influential metric and seconded by NDVI. This is consistent with other studies where it has been suggested that there is a linear relationship between NDVI and malaria cases with the number of breeding sites and NDVI values increasing with the soil moisture where soil moisture (NDWI) is multi-factorial (Eisele et al., 2003; Gemperli et al., 2006; Rogers et al., 2002). The identification of mosquito breeding habitat is a vital step towards malaria control and its subsequent elimination. Therefore, remote sensing data integrated with GIS can be used to develop a malaria early warning system (MEWS) by combining factors influencing malaria transmission (the environmental, climatic and social; population and immigration) in a model form, hence help in facilitating prediction, forecasting and real-time monitoring of incidences with specific reference to geographic areas for prioritization of intervention.

\section{Acknowledgements}

Thanks to the University of Pretoria, Centre for Sustainable Malaria Control for their support. We also appreciate department of health, Mpumalanga Province for the release of malaria data.

\section{Disclosure statement}

No potential conflict of interest was reported by the authors.

\section{Funding}

This study was funded by the EU project QWeCI (Quantifying Weather and Climate Impacts on health in developing countries; funded by the European Commission's Seventh Framework Research Programme under the [grant number 243964]). 


\section{References}

Adimi, F., Soebiyanto, R. P., Safi, N., \& Kiang, R. (2010). Towards malaria risk prediction in Afghanistan using remote sensing. Malaria Journal, 9, 125-136.

Artis, D. A., \& Carnahan, W. H. (1982). Survey of emissivity variability in thermography of urban areas. Remote Sensing of Environment, 12, 313-329.

Beck, L. R., Lobitz, B. M., \& Wood, B. L. (2000). Remote sensing and human health: New sensors and new opportunities. Emerging Infectious Disease Journal, 6, 217-227.

Bi, P., Tong, S., Donald, K., Parton, K., \& Ni, J. (2003). Climatic variables and transmission on malaria: A 12 year data analysis in Schuchen county, China. Public Health Reports, US Government Printing Office, 18, 65-75.

Bogh, C., Lindsay, S. W., Clarke, S. E., Dean, A., Jawara, M., Pinder, M., \& Thomas, C. J. (2007). High spatial resolution mapping of malaria transmission risk in the Gambia, West Africa, using Landsat TM satellite imagery. The American Journal of Tropical Medicine and Hygiene, 76, 875-881.

Booman, M., Durrheim, D. N., La Grange, K., Martin, C., Mabuza, A. M., Zitha, A., ... Sharp, B. L. (2000). Using a geographical information system to plan a malaria control programme in South Africa. Bulletin of the World Health Organisation, 78, 1438-1444.

Booman, M., Sharp, B. L., Martin, C. L., Manjate, B., La Grange, K., \& Durrheim, D. N. (2003). Enhancing malaria control using a computerized management system in southern Africa.

Malaria Journal, 2(13), 1-5.

Britch, S. C., Linthicum, K. J., Anyamba, A., Tucker, C. J., Pak, E. W., Maloney, F. A., ... Miller, M. (2008). Satellite vegetation index data as a tool to forecast population dynamics of medically important mosquitoes at military installations in the continental United States. Military Medicine, 173, 677-683.

Ceccato, P., Connor, S. J., Jeanne, I., \& Thomson, M. C. (2005). Application of geographical information systems and remote sensing technologies for assessing and monitoring malaria risk. Parassitologia, 47, 81-96.

Charoenpanyanet, A., \& Chen, X. (2008). Satellite-based modelling of anopheles mosquito densities onheterogeneous land cover in Western Thailand. The International Archives of the Photogrammetry, Remote Sensing and Spatial Information Sciences, 37, 159-164.

Colombi, A., De Michele, C., Pepe, M., Rampini, A., \& Rossi, S. (2007). Estimation of daily mean air temperature from MODIS land surface temperature data in alpine areas. In Proceedings of EARSeL eProceedings, 6, 38-46.

Coleman, M., Mabuza, A., Kok, G., Coetzee, M., \& Durrheim, D. (2009). Using the SaTScan method to detect local malaria clusters for guiding control programmes. Malar J. 8, 68-73.

Cummins, B., Cortez, R., Foppa, I. M., Walbeck, J., \& Hyman, J. M. (2012). A spatial model of mosquito host-seeking behavior. PLoS Computational Biology, 8, 5-17. doi:10.1371/journal.pcbi.1002500).

Eastman, J. R., Jin, W., Kyem, P. A. K., \& Toledano, J. (1995). Raster procedures for multi-criteria/ multi-objective decisions. PhotogrammetricEngineering and Remote Sensing, 61, 539-547. Eisele,

T. P., Keating, J., Swalm, C., Mbogo, C. M., Githeko, A. K., Regens, J. L., ... Beier, J. C. (2003). Linking field-based ecological data with remotely sensed data using a geographic information system in two malaria endemic urban areas of Kenya. Malaria Journal, 2, 44-60.

Gaudart, J., Touré, O., Dessay, N., Dicko, A. L., Ranque, S., Forest, L., ... Doumbo, O. K. (2009). Modelling malaria incidence with environmental dependency in a locality of Sudanese savannah area, Mali. Malaria Journal, 8, 61-76.

Gemperli, A., Sogoba, N., Fondjo, E., Mabaso, M., Bagayoko, M., Briet, O. J. T., ... Vounatsou, P. (2006). Mapping malaria transmission in West and Central Africa. Tropical Medicine and International Health, 11, 1032-1046.

Gu, W., \& Novak, R. J. (2005). Habitat-based modelling of impacts of mosquito larva interventions on entomological inoculation rates, incidence, and prevalence of malaria. The American Journal of Tropical Medicine and Hygiene, 73, 546-552.

Gyanesh, C., Brian, L. M., \& Dennis, L. H. (2009). Summary of current radiometric calibration coefficients for Landsat MSS, TM, ETM+, and EO-1 ALI sensors. Remote Sensing of Environment, 113, 893-903. 
Hay, S. I., Snow, R. W., \& Rogers, D. J. (1998). Predicting malaria seasons in Kenya using multitemporal meteorological satellite sensor data. Transactions of the Royal Society of Tropical Medicine and Hygiene, 92, 12-20.

Hopp, M. J., \& Foley, J. A. (2001). Global-scale relationships between climate and the dengue fever vector Aedes aegypti. Climatic Change, 48, 441-463.

Kleinschmidt, I., Sharp, B. L., Clarke, G. P. Y., Curtis, B., \& Fraser, C. (2001). Use of generalized linear mixed models in the spatial analysis of small-area malaria incidence rates in KwaZulu Natal, South Africa. American Journal of Epidemiology, 153, 1213-1221.

Landsat Project Science Office. (2002). Landsat 7 science data user's hand-book. Washington, DC. Goddard space flight center, NASA.

Le Sueur, D., Ngxongo, S., Sharp, B. L., Martin, C., Fraser, C., Teuschner, M., ... Mnzavaae. (1997). Towards a spatial rural information system. A Publication of the Health System Trust with the Medical Research Council, 1-46.

Le Sueur, D., Ngxongo, S., Stunaford, M., Sharp, B. L., Maharaj, R., Martin, C., \& Brown, D. (1994). Towards a rural information system. Proceedings of an International Workshop held in Colombo, Sri Lanka. 5-10 September. 766, 35-50.

Machault, V., Vignolles, C., Borchi, F., Vounatsou, P., Pages, F., Briolant, S., ... Rogier, C. (2011). The use of remotely sensed environmental data in the study of malaria. Geospatial Health, 5, 151-168.

Martin, C., Curtis, B., Fraser, C., \& Sharp, B. L. (2002). The use of a GIS-based malaria information system for malaria research and control in South Africa. Health \& Place, 8, 227-236. Masuoka,

P., Claborn, D., Andre, R., \& Nigro, J. (2003). Use of IKONOS and Landsat for malaria control in the Republic of Korea. Remote Sensing of Environment, 88, 187-194.

McFeeters, S. K. (2013). Using the normalized difference water index (NDWI) within a geographic information system to detect swimming pools for mosquito abatement: A practical approach. Remote Sensing, 5, 3544-3561. doi:10.3390/rs5073544

Mouchet, J., Carnevale, P., Coosemans, M., Julvez, J., Manguin, S., Richard-Lenoble, D., \& Sircoulon, J. (2004). Biodiversité du paludisme dans le monde [Biodiversity of malaria worldwide]. Montrouge: John Libbey Eurotext.

Nihei, N., Hashida, Y., Kobayashi, M., \& Ishii, A. (2002). Analysis of malaria endemic areas on the Indochina Peninsula using remote sensing. Japanese Journal of Infectious Diseases, 55, 160-166.

Qinqin, S., Jianjun, T., \& Yonghang, X. (2010). An ERDAS image processing method for retrieving LST and describing urban heat evolution: A case study in the Pearl River Delta Region in South China. Environmental Earth Sciences, 59, 1047-1055.

Rogers, D. J., Randolph, S. E., Snow, R. W., \& Hay, S. I. (2002). Satellite imagery in the study and forecast of malaria. Nature, 415, 710-715.

Rouse, J. W., Haas, R. H., Schell, J. A., Deering, D. W. (1973). Monitoring vegetation systems in the great plains with ERTS. In S. C. Fraden, E. P. Marcanti, \& M. A. Becker (Eds.), Third ERTS-1 symposium (pp. 309-317). Washington, DC: NASA.

Sharp, B. L., Craig, M., Curtis, B., Mnzava, A., Maharaj, R., Kleinschmidt, I. (2000). Review of malaria in South Africa. In South African health review (pp. 351-364). Durban: Health Systems Trust.

Sharp, B. L., Fraser, C., Naidoo, K., Dlungwane, M. (1999). Computer assisted health information system for malaria control. Presented at the MIM (Multilateral Initiative on Malaria) African Malaria Conference, 14-19 March 1999, Durban, South Africa.

Statistics South Africa. (2013). Mid-year population estimates. Pretoria: Statistics South Africa.

Stephen, M. (2006). Landscape determinants and remote sensing of mosquito larval habitats in the high land of Kenya. Malaria Journal, 5, 13-23.

South Africa National Department of Health: National Malaria Control Policy. (2007). Pretoria: South Africa National Department of Health.

Sutherst, R. W. (2004). Global change and human vulnerability to vector-borne diseases. Clinical Microbiology Reviews, 17, 136-173.

Vancutsem, C. P., Ceccato, P., Dinku, \& Connor, S. J. (2010). Evaluation of MODIS land surface temperature data to estimate air temperature in different ecosystems over Africa. Remote Sensing of Environment, 114, 449-465. 
World Health Organization. (2013a). Country report; progress and impact series, 2013. South Africa: Focus on South Africa, National Department of Health.

World Health Organization. (2013b). The Africa malaria report, 2013. Geneva: World Health Organization.

Xu, H. (2006). Modification of normalised difference water index (NDWI) to enhance open water features in remotely sensed imagery. International Journal of Remote Sensing, 27, 3025-3033.

Zou, L., Miller, S. N., \& Schmidtmann, E. T. (2006). Mosquito larval habitat mapping using remote sensing and GIS: Implications of coalbed methane development and west Nile virus. Journal of Medical Entomology, 43, 1034-1041. 